\title{
Mathematical Modeling and Analysis of Different Vector Controlled CSI Fed 3-Phase Induction Motor Drive
}

\author{
Arul Prasanna Mark, Rajasekaran Vairamani, and Gerald Christopher Raj Irudayaraj \\ Department of EEE, PSNA College Engineering \& Technology, Dindigul, Tamilnadu 624622, India \\ Correspondence should be addressed to Arul Prasanna Mark; arulprasanna@psnacet.edu.in
}

Received 2 April 2014; Accepted 26 May 2014; Published 9 July 2014

Academic Editor: Kerim Guney

Copyright (C) 2014 Arul Prasanna Mark et al. This is an open access article distributed under the Creative Commons Attribution License, which permits unrestricted use, distribution, and reproduction in any medium, provided the original work is properly cited.

\begin{abstract}
The main objective of this paper is to build a simple mathematical competent model that describes the circuits and interconnections of a 3-phase squirrel cage induction motor used for industrial applications. This paper presents the detailed analysis of theoretical concepts used in mathematical modeling, simulation' and hardware implementation. The objective of this work is to compare the dynamic performances of the vector control methods for CSI fed IM drives. Based on the results, dynamic performances of the proposed drives are individually analysed using the sensitivity tests. The tests that are chosen for the comparison are step changes in the reference speed and torque of the motor drive. Here the IM is mathematically modeled in different reference frames for input output linearization (IOL) control, field oriented control (FOC), and direct torque control method (DTC) which are designed using hardware equivalent mathematical equations. The most important contributions in this paper are mathematical simulation structure of IM model in rotor flux frame using current and speed that were developed and implemented in MATLAB-Simulink. The operation and performance of the different vector control methods are verified by simulation using MATLAB/SIMULINK and experimental results.
\end{abstract}

\section{Introduction}

The alternating current (AC) motor, especially asynchronous three-phase induction motor (IM), has been the motor of choice in industrial settings for about the past half century as power electronics can be used to control its output behavior. Before that, the direct current (DC) motor, especially the separately excited one was widely used because of its easy speed and torque controllability. The IM is a rugged structure motor because it is brushless and has very fewer internal parts that need maintenance or replacement. This makes it cheaper in comparison to other motors, such as the DC motor. Thus, IM and its drive system have been gaining market share in industry and even in alternative applications such as hybrid electric vehicles. For variable speed electric motor applications in low to moderate power, pulse width modulation (PWM) with voltage source inverter (VSI) is usually used. However, the switched voltages produce high voltage slopes over the stator windings, which stress the insulations and cause bearing current problems. A possible solution is to use
PWM with current source inverter (CSI). Phillips [1], Lipo and Cornell [2], Palaniappan et al. [3], Kaimoto et al. [4], Krishnan et al. [5], Kazmierkowski and Koepcke [6], and Hombu et al. [7] tried to develop the CSI and make it suitable for ac motor (especially IM) variable speed drives; since both stator current and voltage waveforms are close to the sinusoidal waveform, the above problems are reduced. Further, CSI can be used for high power applications. In the recent years, the high performance CSI fed variable speed drives, especially IM drives have been dominated by various control methods. The important methods are vector based $V / f$ control, input output linearization (IOL) control, indirect field oriented control (IFOC), and direct torque control (DTC) as each method has its own unique features. $V / f$ is by far the simplest drive since it requires no parameter knowledge and is essentially an open loop drive. IOL is one type of nonlinear state feedback control which is completely input-output decoupled at all times even in transients. IFOC offers similar dynamic torque control performance to that of DC motors, giving fast, near step changes in machine torque 
and DTC provides simpler control architecture with a similar dynamic performance as that of IFOC.

Similar studies of vector controlled inverter fed drives are discussed mostly with the voltage source inverters and very few papers are available with the study of vector controlled current source inverters; Veerachary [8], Salo and Tuusa [9], and Babaei and Heydari [10]. This paper presents a comparative analysis of different mathematical modeling of vector controlled CSI fed induction motor drives and in particularly the dynamic responses of the drive motor speed against change in speed as well as the torque references in a single simulation cycle and verified experimentally and to ascertain different mathematical dynamic IM modeling for CSI fed drives as Holmes et al. [11] and to apply control methods on them. The MATLAB s-functions are described to design IM modeling and drives. Finally, the above mentioned drive strategies are compared as fairly as possible by comparing their dynamic responses when there is step change in the references (usually stator currents, motor speed, and load torque).

\section{Mathematical Modeling of 3-Phase Induction Motor Drive}

In this section, Mathematical model of IM is shown in Figure 1 and described. In general, IM is used to transform electrical energy to mechanical energy. It consists of electric circuitry, electromagnetic circuitry, and electromechanic circuitry Krishnan [12]. The main objective of the motor modeling is to build a simple but competent model that describes these circuits and their interconnections. The main path in the model is in relation with the voltage or current and the stator phases in input and magnetic flux inside the motor and electromagnetic torque in the output.

As mentioned earlier, the squirrel cage IM is prepared for industry applications. The IM can either be supplied by a voltage source or a current source. These sources are assumed to be ideal; this means that they can supply any desired voltage or current without losses. According to Krause and Thomas [13], the basic equations of the IM are the stator voltage equation (1), the rotor voltage equation (2), the equations of the flux linkages of the stator, and the rotor winding systems, (3) and (4), and the torque equation (5). Consider the following:

$$
\begin{gathered}
v_{s}^{s}=R_{s} i_{s}^{s}+\dot{\lambda}_{s}^{s}, \\
v_{r}^{r}=0=R_{r} i_{r}^{r}+\dot{\lambda}_{r}^{r}, \\
\lambda_{s}^{a}=\lambda_{m}^{a}+L_{l s} i_{s}^{a}, \\
\lambda_{r}^{a}=\lambda_{m}^{a}+L_{l r} i_{r}^{a}, \\
T_{e}=\left[C\left(\frac{\pi}{2}\right) \lambda_{m}^{a}\right]^{T} i_{s}^{a} .
\end{gathered}
$$

The equations are given in vector format Bose [14]. Every vector variable has two components: the first component is parallel to the reference frame axis or " $d$ " axis and the second component is perpendicular to the reference axis or " $q$ " axis.
The symbols are $v$-voltage, $i$-current, $\lambda_{m}$-flux linkage, $R$-resistance, and $L_{l}$-leakage inductance; subscript " $s$ " indicates the stator winding system, " $r$ ", the rotor winding system; superscript " $s$ " indicates the stator reference frame (stator coordinates), " $r$ ", the rotor reference frame, and " $a$ ", any arbitrary reference frame $T_{e}$ is the electromagnetic torque; $C(\pi / 2)$ is a rotation matrix over $\pi / 2$ radians; the dot (') indicates a time derivative. The stator voltage equation is restricted to the stator reference frame because of the differential of the stator flux vector, whereas the rotor voltage equation is restricted to the rotor reference frame because of the differentiation. The flux equations and the torque equation can be defined in any reference frame, denoted by superscript " $a$."

It is evident from (1) to (5) that the motor voltage, flux, and torque can be controlled easily by controlling the current of the motor. So, the CSI is the right choice to control the motor directly because the inputs of the current fed IM model are the stator currents.

Before these equations are completed to obtain the IM model, the reference frame of the model in relation to the problem being investigated and the type of computer (analog or digital) are chosen. In order to evaluate the usefulness of each reference frame, the above equations are simulated using Matlab software to predict the transient performance of an IM.

The mathematical modeling of 3-phase induction motor drive which can be run at any of the three rotating reference frame models, namely, stator rotating reference frame, rotor rotating reference frame, and synchronous rotating reference frame in Matlab/Simulink is shown below in Figure 2.

\section{Transient Performance of Different Mathematical Reference Frame Models}

Figure 3 shows the transient performance of " $a$ " phase and $d$-axis stator currents in each reference frame when there is a step change in the reference torque from 0 to full load at 1.4 seconds. From Figure 3(a), it is evident that in stator or stationary reference frame stator $d$-axis current behaves exactly the same way as do the stator " $a$ " phase current of the motor. If the stationary reference frame is used, then the stator $d$-axis current is identical to the stator phase current. This would be useful when interest is specifically confined to stator variables, for example, variable speed stator-fed IM drives. Similarly, if the rotor reference frame is used then the rotor $d$-axis current will behave in exactly the same manner as the rotor " $a$ " phase current. This would be useful when interest is confined to rotor variables only, as, for example, variable speed rotor-fed IM drives. From Figure 3(b), it is evident that in rotor rotating reference, frame stator $d$-axis current does not behave as the stator phase current. From Figure 3(c), it is apparent that in synchronously rotating reference frame, stator $d$-axis current behaves like DC quantity. If the synchronously rotating reference frame is used, then the stator and rotor current behave like DC quantity. Thus, the controller design is simple and is widely used in AC drives. 




FIGURE 1: Induction motor modeling in arbitrary reference frame.

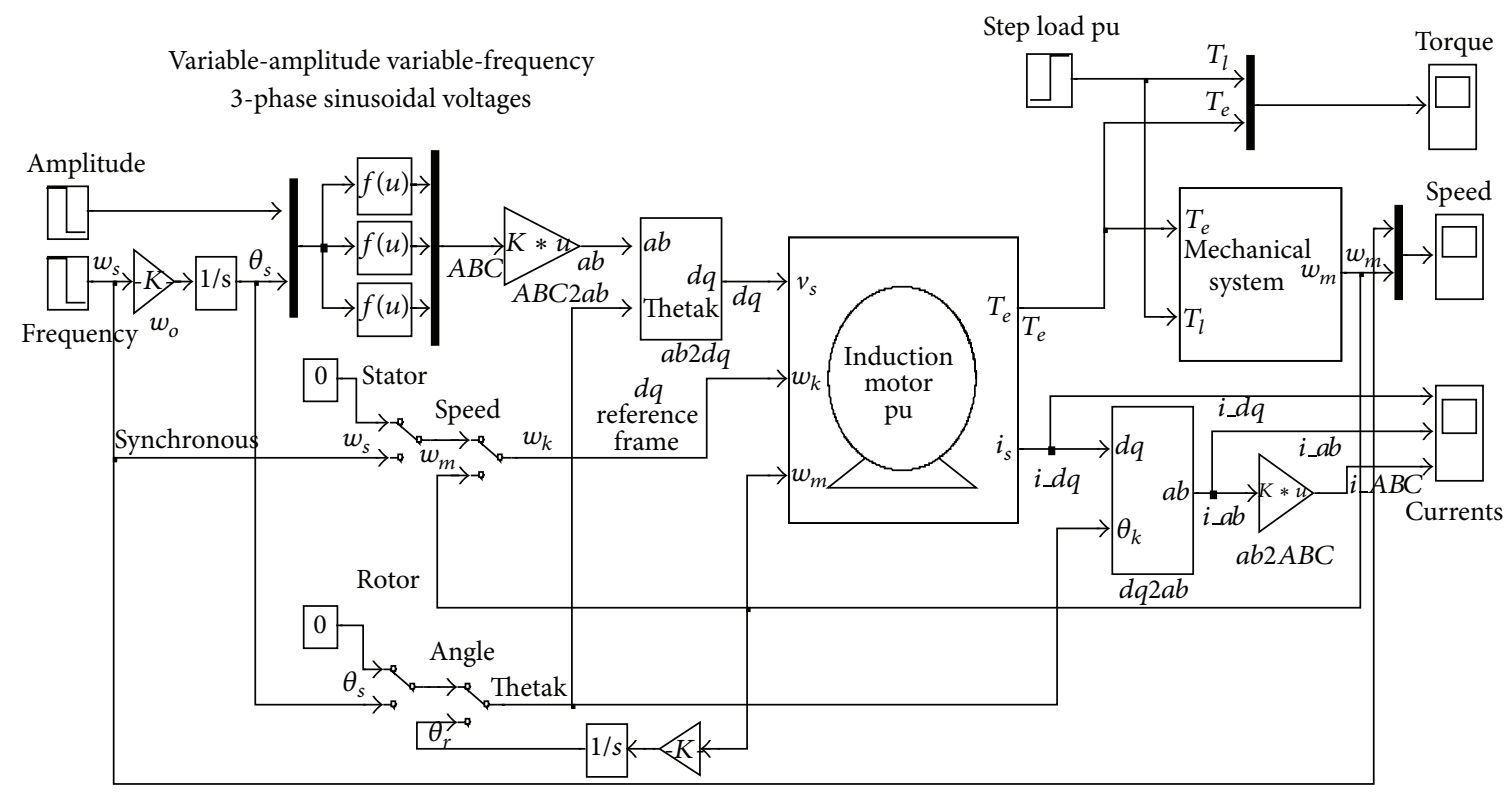

Figure 2: Mathematical modeling of 3-phase induction motor drive.

Figure 4 shows the transient performance of $q$-axis stator current and $d$-rotor flux in each reference frame when there is a step change in the reference torque from 0 to full load at 1.4 seconds. From Figures 4(a) and 4(b), it is apparent that there is a coupling effect between stator $q$-axis current and rotor $d$-axis flux. So, independent control is difficult. Figure 4(c) shows that the rotor $d$-axis flux and stator $q$ axis current (control variables) have linear relationship with torque (speed). Thus, it is useful in the rotor flux oriented (RFO) control methods.

Figure 5 shows the transient performance of $q$-axis stator current and $d$-stator flux in each reference frame when there is a step change in the reference torque from 0 to full load at 1.4 seconds. Figures 5(a) and 5(b) state that there is a coupling effect between stator $q$-axis current and stator $d$-axis flux and so independent control is difficult. From 


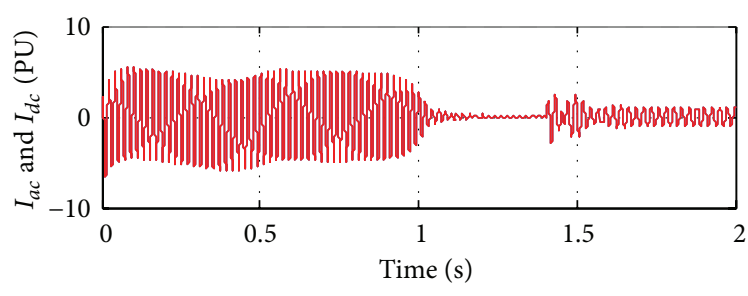

(a)

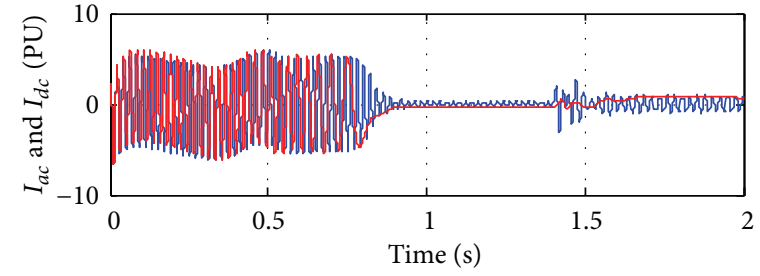

(b)



- Stator $a$ phase current

_ Stator $b$-axis current

(c)

FIGURE 3: Simulated results of " $a$ " phase and $d$-axis stator currents in different rotating reference frames.



(a)



(b)

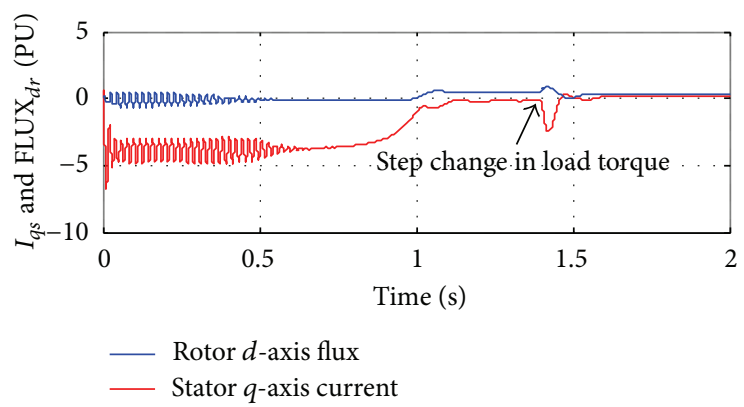

(c)

FIGURE 4: Simulated results of $q$-axis stator current and $d$-axis rotor flux in different rotating reference frames.

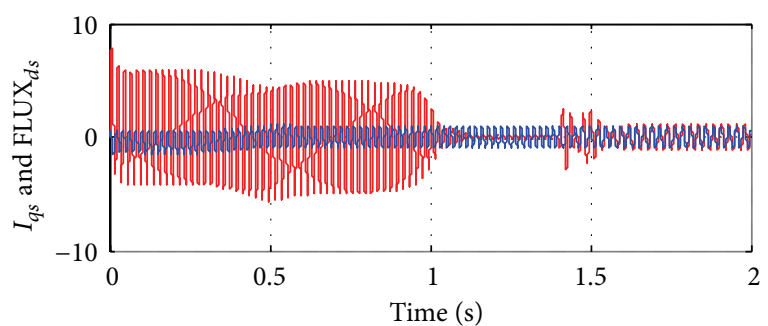

(a)

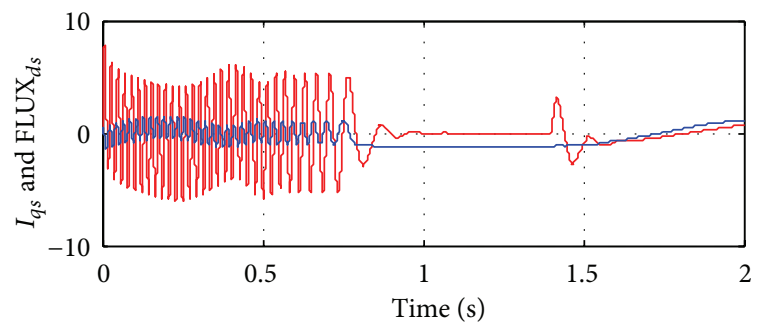

(b)

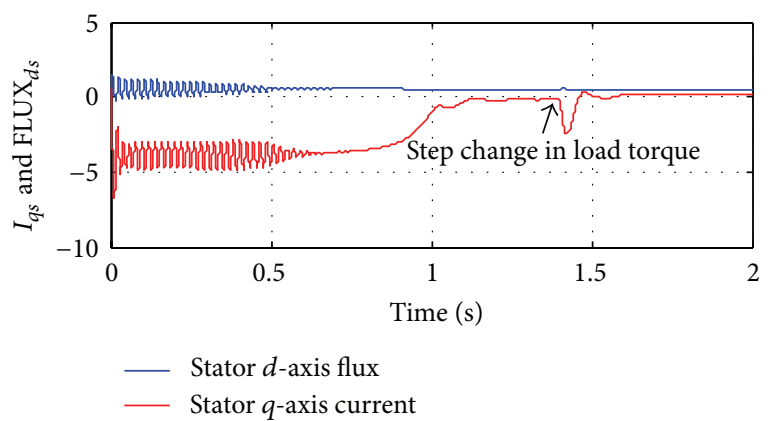

(c)

FIGURE 5: Simulated results of $q$-axis stator current and $d$-axis stator flux in different rotating reference frames. 
Figure 5(c), it is evident that the stator $d$-axis flux and stator $q$ axis current (control variables) have linear relationship with torque (speed). It is used in the stator flux oriented (SFO) control methods.

The basic IM equations from Krause et al. [15] are simulated for three different reference frames using MATLAB 7.6 software and the results obtained are compared with each reference frame. From the comparison, it is observed that if the stator rotating reference frame is used, then stator $d$-axis current is identical to that of the stator " $a$ " phase current as shown in Figure 3(a), which is used in stator fed IM drives. Similarly, in rotor reference frame, rotor $d$-axis current is identical to the rotor " $a$ " phase current and useful in rotor fed IM drives. If the synchronous reference frame is used, then the stator $d$-axis current behaves like DC quantity as shown in Figure 3(c). From Figures 4(c) and 5(c), it is evident that synchronous reference frame is useful in RFO and SFO drive control methods. In this paper, synchronous reference frame is preferred to model the IM in $V / f$, IOL control methods. RFO control is used in IFOC method and SFO is used in DTC method.

\section{IOL Control for CSI Fed IM Drives}

In this section, a type of IOL control method for the CSI fed IM drive is described. The controller is designed based on pole placement technique of Wonham [16] to a $d$ - $q$ axis state space linearized model of the drive which includes a reduced order rotor current observer. A control law has been developed to improve the dynamic response of the drive by using the concepts from Veerachary [8] which includes feed forward as well as feedback controls.

4.1. Mathematical Modeling of IOL Control Method. The equivalent circuit for the CSI, capacitor, and IM in a $d$ $q$ axis rotating reference frame is shown in Figure 6. The corresponding state equation (differential equations) with motor flux linkages as variables is derived from Wu et al. [17].

Veerachary [8] presented the linearized CSI-IM drive state space model in synchronously rotating reference frame as follows:

$$
\dot{x}=A x+B u,
$$

where

$$
\begin{aligned}
& \dot{x}=\frac{d x}{d t}, \\
& y=C x,
\end{aligned}
$$

where,

$$
\begin{aligned}
& x=\left[\begin{array}{c}
\Delta i_{q s} \\
\Delta i_{q r}^{\prime} \\
\Delta i_{d r}^{\prime} \\
\frac{\Delta \omega_{r}}{\omega_{b}}
\end{array}\right], \quad \dot{x}=\frac{d}{d t}\left[\begin{array}{c}
\Delta i_{q s} \\
\Delta i_{q r}^{\prime} \\
\Delta i_{d r}^{\prime} \\
\frac{\Delta \omega_{r}}{\omega_{b}}
\end{array}\right], \quad u=\left[\begin{array}{c}
\Delta V_{d}^{\prime} \\
\frac{\Delta \omega_{e}}{\omega_{b}} \\
\Delta T_{L}
\end{array}\right], \quad y=\left[\begin{array}{c}
\Delta i_{q s} \\
\frac{\Delta \omega_{r}}{\omega_{b}}
\end{array}\right], \\
& A=\left[\begin{array}{cccc}
-\frac{x_{r}^{\prime} r_{0} \omega_{b}}{x_{0} x_{r}^{\prime}-x_{m}^{2}} & \frac{x_{m} R_{r}^{\prime} \omega_{b}}{x_{0} x_{r}^{\prime}-x_{m}^{2}} & -\frac{\omega_{e 0} x_{r}^{\prime} x_{m}(1-s)}{x_{0} x_{r}^{\prime}-x_{m}^{2}} & -\frac{x_{m} x_{r}^{\prime} i_{d r 0}^{\prime} \omega_{b}}{x_{0} x_{r}^{\prime}-x_{m}^{2}} \\
\frac{\omega_{b} x_{m} r_{0}}{x_{0} x_{r}^{\prime}-x_{m}^{2}} & -\frac{x_{0} R_{r}^{\prime} \omega_{b}}{x_{0} x_{r}^{\prime}-x_{m}^{2}} & \frac{\omega_{e 0}\left(x_{m}^{2}-s x_{0} x_{r}^{\prime}\right)}{x_{0} x_{r}^{\prime}-x_{m}^{2}} & \frac{x_{0} x_{r}^{\prime} i_{d r 0}^{\prime} \omega_{b}}{x_{0} x_{r}^{\prime}-x_{m}^{2}} \\
\frac{s \omega_{e 0} x_{m}}{x_{r}^{\prime}} & s \omega_{e 0} & -\frac{\omega_{b} R_{r}^{\prime}}{x_{r}^{\prime}} & -\frac{\omega_{b}\left(x_{m} i_{q s 0}+x_{r}^{\prime} i_{q r 0}^{\prime}\right)}{x_{r}^{\prime}} \\
\frac{x_{m} i_{d r 0}^{\prime}}{2 H} & 0 & \frac{x_{m} i_{q s 0}}{2 H} & 0
\end{array}\right] \text {, } \\
& B=\left[\begin{array}{ccc}
\frac{x_{r}^{\prime} \omega_{b}}{x_{0} x_{r}^{\prime}-x_{m}^{2}} & 0 & 0 \\
\frac{-x_{m} \omega_{b}}{x_{0} x_{r}^{\prime}-x_{m}^{2}} & -\omega_{b} i_{d r 0}^{\prime} & 0 \\
0 & -\frac{\omega_{b}\left(x_{m} i_{q s 0}+x_{r}^{\prime} i_{q r 0}^{\prime}\right)}{x_{r}^{\prime}} & 0 \\
0 & -\frac{1}{2 H}
\end{array}\right], \quad C=\left[\begin{array}{cccc}
1 & 0 & 0 & 0 \\
0 & 0 & 0 & 1
\end{array}\right], \\
& V_{d}^{\prime}=\frac{\pi V_{\mathrm{dc}}}{3 \sqrt{3}}, \quad r_{0}=R_{s}+\frac{\pi^{2} R_{\mathrm{dc}}}{18}, \quad x_{0}=x_{s}+\frac{\pi^{2} x_{d}}{18} .
\end{aligned}
$$






FIGURE 6: Equivalent circuit of CSI-IM section.

With usual state feedback control, there can be the tracking error in steady state. To eliminate this error, Smith and Davidson [18] introduced an integral control which includes feedback as well as feed forward control. In this work, an optimal control law is derived by using the concepts of Smith and Davidson [18] and Veerachary [8].

4.2. Design of Optimal Control Law. A new multivariable optimal controller incorporating state feedback as well as feed forward control for fast regulation and stability of a CSI fed IM drive is presented in this section. The design of the state feedback controller is based on the industrial regulator theory together with pole placement technique applied on a linearized $d-q$ axes state space model of the drive and includes a reduced order observer to estimate the inaccessible states like $d-q$ axes rotor currents. A feed forward control in terms of reference and disturbance inputs has been added to the feedback controller-observer to obtain faster dynamic response either from (10) or (11) as follows (Figure 7):

$$
u=K_{1} x+K_{2} \int_{0}^{t}\left(y-y_{r}\right) d t+K_{F F}\left[\begin{array}{l}
d \\
y_{r}
\end{array}\right]
$$

or

$$
\begin{gathered}
u=K_{1(2 \times 4)}\left[\begin{array}{c}
\Delta i_{q s} \\
\Delta i_{q r}^{\prime} \\
\Delta i_{d r}^{\prime} \\
\frac{\Delta \omega_{r}}{\omega_{b}}
\end{array}\right]+K_{2(2 \times 2)}\left[\begin{array}{l}
\int_{0}^{t}\left(i_{q s}-i_{q s}^{*}\right) d t \\
\int_{0}^{t}\left(\omega_{r}-\omega_{r}^{*}\right) d t
\end{array}\right] \\
+K_{F F(2 \times 3)}\left[\begin{array}{c}
T_{L} \\
i_{q s}^{*} \\
\omega_{r}^{*}
\end{array}\right] .
\end{gathered}
$$

\section{IFOC for CSI Fed IM Drives}

In this section, a high performance current fed indirect RFO control method is described for IMs. The IM is mathematically modeled in the rotor flux reference frame that is

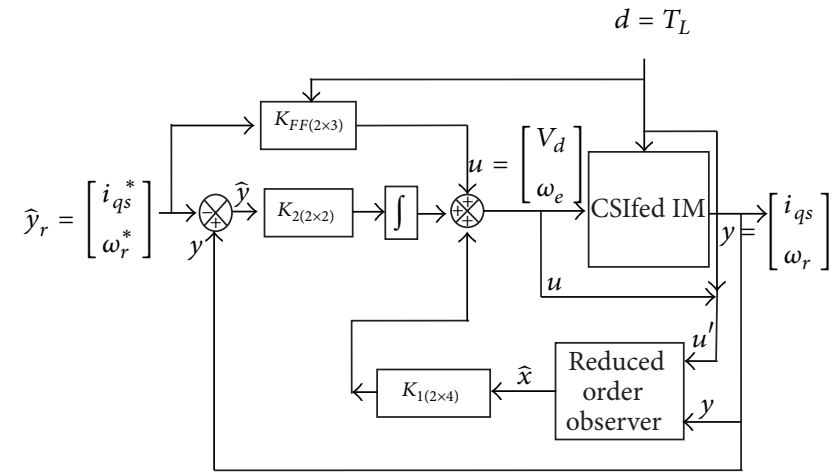

FIGURE 7: Combined feed forward and integral feedback controller.

presented. The rotor flux orientation is also obtained. In the low speed region, the rotor flux components can be synthesized more easily with the help of speed and current signals. Design of indirect vector controller Blaschke $[19,20]$ and rotor flux estimator is discussed. Implementation of IFOC to CSI fed IM drive and transient response analysis of other simulation results are also discussed.

5.1. Mathematical Modeling of IFO Control Method. The rotor equations of the IM containing flux linkages as variables are given by Krause et al. [15] as follows:

$$
\begin{aligned}
& R_{r} i_{d r}^{e}+p \lambda_{d r}^{e}-\left(\omega_{e}-\omega_{r}\right) \lambda_{q r}^{e}=0, \\
& R_{r} i_{q r}^{e}+p \lambda_{q r}^{e}+\left(\omega_{e}-\omega_{r}\right) \lambda_{d r}^{e}=0,
\end{aligned}
$$

where

$$
\omega_{\mathrm{sl}}=\omega_{e}-\omega_{r}
$$

then (12) becomes

$$
\begin{aligned}
& R_{r} i_{d r}^{e}+p \lambda_{d r}^{e}-\omega_{\mathrm{sl}} \lambda_{q r}^{e}=0, \\
& R_{r} i_{q r}^{e}+p \lambda_{q r}^{e}+\omega_{\mathrm{sl}} \lambda_{d r}^{e}=0 .
\end{aligned}
$$

The resultant rotor flux linkage, $\lambda_{r}$, also known as the rotor flux linkages phasor, is assumed to be on the direct axis to reduce the number of variables in the equations by one. Moreover, it relates to reality that rotor flux linkages are a single variable. Hence, aligning $d$ axis with rotor flux phasor yields

$$
\begin{gathered}
\lambda_{r}=\lambda_{d r}^{e}, \\
\lambda_{q r}^{e}=0, \\
p \lambda_{q r}^{e}=0 .
\end{gathered}
$$

Substituting (15) into (14) results in the new rotor equations as follows:

$$
\begin{aligned}
& R_{r} i_{d r}^{e}+p \lambda_{r}=0, \\
& R_{r} i_{q r}^{e}+\omega_{\mathrm{sl}} \lambda_{r}=0 .
\end{aligned}
$$


The rotor currents in terms of the stator currents are derived from (18) as

$$
\begin{gathered}
i_{q r}^{e}=-\frac{L_{m}}{L_{r}} i_{q s}^{e}, \\
i_{d r}^{e}=\frac{\lambda_{r}}{L_{r}}-\frac{L_{m}}{L_{r}} i_{d s}^{e}, \\
i_{d s}^{e}=i_{f}=\left[1+\frac{L_{r}}{R_{r}} p\right] \frac{\lambda_{r}}{L_{m}}, \\
i_{d s}^{e}=i_{f}=\left[1+\tau_{r} p\right] \frac{\lambda_{r}}{L_{m}}, \\
\omega_{\mathrm{sl}}=\frac{R_{r} L_{m}}{L_{r}} \frac{i_{q s}^{e}}{\lambda_{r}}, \\
\omega_{\mathrm{sl}}=\frac{R_{r} L_{m}}{L_{r}} \frac{i_{T}}{\lambda_{r}}, \\
\omega_{\mathrm{sl}}=\frac{L_{m}}{\tau_{r}} \frac{i_{T}}{\lambda_{r}} .
\end{gathered}
$$

The $q$ - and $d$-axes currents are relabeled as torque $\left(i_{T}\right)$ and flux producing $\left(i_{f}\right)$ components of the stator-current phasor, respectively. $\tau_{r}$ denotes rotor time constant. Similarly, by the same substitution of the rotor currents from (19) into torque expression, the electromagnetic torque is derived as

$$
\begin{gathered}
T_{e}=\frac{3}{2} \frac{P}{2} \frac{L_{m}}{L_{r}}\left(\lambda_{d r}^{e} i_{q s}^{e}-\lambda_{q r}^{e} i_{d s}^{e}\right) \\
T_{e}=\frac{3}{2} \frac{P}{2} \frac{L_{m}}{L_{r}}\left(\lambda_{d r}^{e} i_{q s}^{e}\right) \\
T_{e}=K_{t e} \lambda_{r} i_{q s}^{e}=K_{t e} \lambda_{r} i_{T},
\end{gathered}
$$

where the torque constant $K_{t e}$ is defined as

$$
K_{t e}=\frac{3}{2} \frac{P}{2} \frac{L_{m}}{L_{r}} .
$$

Note that the torque is proportional to the product of rotor flux linkage and the stator $q$-axis current. This resembles the air gap torque expression of the DC motor which is proportional to the product of the field flux linkages and the armature current. If the rotor flux linkage is maintained as constant, the torque is proportional to the torque producing component of the stator current. This is in relation to the separately excited DC motor with armature current control, where the torque is proportional to the armature current when the field current is constant. Further, here too, the time constant is measured in the order of a few milliseconds. The rotor flux linkages and air gap torque given in (21) and (22), respectively, complete the transformation of the IM into an equivalent separately-excited dc motor from a control point of view.

5.2. Design of IFO Controller. The IFO controller was designed using the concepts of Vas [21] and Salo and Tuusa [9].
From that the stator-current phasor is the phasor sum of the $d$ - and $q$-axis stator currents in any frames and it is given as

$$
i_{s}=\sqrt{\left(i_{q s}^{e}\right)^{2}+\left(i_{d s}^{e}\right)^{2}}
$$

and the $d q$ axes $(2 \phi)$ to $(3 \phi)$ abc phase current relationship is obtained from

$$
\begin{aligned}
& {\left[\begin{array}{c}
i_{q s}^{e} \\
i_{d s}^{e}
\end{array}\right]} \\
& \quad=\frac{2}{3}\left[\begin{array}{lll}
\cos \theta_{f} & \cos \left(\theta_{f}-\frac{2 \pi}{3}\right) & \cos \left(\theta_{f}+\frac{4 \pi}{3}\right) \\
\sin \theta_{f} & \sin \left(\theta_{f}-\frac{2 \pi}{3}\right) & \sin \left(\theta_{f}+\frac{4 \pi}{3}\right)
\end{array}\right]\left[\begin{array}{c}
i_{a s} \\
i_{b s} \\
i_{c s}
\end{array}\right] .
\end{aligned}
$$

And it can be written as

$$
i_{q d}=[T]\left[i_{a b c}\right]
$$

where

$$
\begin{aligned}
& i_{q d}=\left[\begin{array}{ll}
i_{q s}^{e} & i_{d s}^{e}
\end{array}\right]^{t}, \\
& i_{a b c}=\left[\begin{array}{lll}
i_{a s} & i_{b s} & i_{c s}
\end{array}\right]^{t}, \\
& {[T]=\frac{2}{3}\left[\begin{array}{ccc}
\cos \theta_{f} & \cos \left(\theta_{f}-\frac{2 \pi}{3}\right) & \cos \left(\theta_{f}+\frac{2 \pi}{3}\right) \\
\sin \theta_{f} & \sin \left(\theta_{f}-\frac{2 \pi}{3}\right) & \sin \left(\theta_{f}+\frac{2 \pi}{3}\right)
\end{array}\right],}
\end{aligned}
$$

where $i_{a s}, i_{b s}$, and $i_{c s}$ are the three phase stator currents. Note that the elements in the $T$ matrix are cosinusoidal functions of electrical angle, $\theta_{f}$. The electrical field angle in this case is that of the rotor flux-linkages phasor and is obtained as the sum of the rotor and slip angles as follows:

$$
\theta_{f}=\theta_{r}+\theta_{\mathrm{sl}}
$$

and the slip angle is obtained by integrating the slip speed and is given as

$$
\theta_{\mathrm{sl}}=\int \omega_{\mathrm{sl}}
$$

IFO controller, developed from these derivations, accepts the torque and flux requests and generates the torque and flux producing components of the stator-current phasor and the slip-angle commands. The command values are denoted with asterisks throughout this thesis. From (20), (21), and (23), the command values of $i_{T}, i_{f}$, and $\omega_{\mathrm{sl}}$ are obtained as follows:

$$
\begin{gathered}
i_{T}^{*}=\frac{T_{e}^{*}}{K_{t e} \lambda_{r}^{*}}=\left(\frac{2}{3}\right)\left(\frac{2}{P}\right) \frac{T_{e}^{*}}{\lambda_{r}^{*}} \frac{L_{r}}{L_{m}}, \\
i_{f}^{*}=\left(1+p \frac{L_{r}}{R_{r}}\right) \frac{\lambda_{r}^{*}}{L_{m}}, \\
\omega_{\mathrm{sl}}^{*}=\frac{R_{r} L_{m}}{L_{r}} \frac{i_{T}^{*}}{\lambda_{r}^{*}} .
\end{gathered}
$$


The command slip angle, $\theta_{\mathrm{sl}}^{*}$, is generated by integrating $\omega_{\mathrm{sl}}^{*}$. The torque angle command is obtained as the arctangent of $i_{T}^{*}$ and $i_{f}^{*}$. The field angle is obtained by summing the command slip angle and rotor angle. With the torque and flux producing components of the stator current commands and rotor field angle, the $q d$ axes current commands ( $a b c$ phase current commands) are obtained as follows. The relevant steps involved in the realization of the IFO controller are as follows:

$$
\begin{gathered}
{\left[\begin{array}{c}
i_{q s}^{*} \\
i_{d s}^{*}
\end{array}\right]=\left[\begin{array}{cc}
\cos \theta_{f} & \sin \theta_{f} \\
-\sin \theta_{f} & \cos \theta_{f}
\end{array}\right]\left[\begin{array}{c}
i_{T}^{*} \\
i_{f}^{*}
\end{array}\right],} \\
{\left[\begin{array}{c}
i_{a s}^{*} \\
i_{b s}^{*} \\
i_{c s}^{*}
\end{array}\right]=\left[T^{-1}\right]\left[\begin{array}{c}
i_{q s}^{*} \\
i_{d s}^{*} \\
0
\end{array}\right],}
\end{gathered}
$$

where

$$
T^{-1}=\left[\begin{array}{ccc}
1 & 0 & 1 \\
-\frac{1}{2} & -\frac{\sqrt{3}}{2} & 1 \\
-\frac{1}{2} & \frac{\sqrt{3}}{2} & 1
\end{array}\right] .
$$

By using (35) to (37), the stator $q$ - and $d$-axes and abc current commands are derived as

$$
\begin{gathered}
i_{q s}^{*}=\left|i_{s}^{*}\right| \sin \theta_{s}^{*}, \\
i_{d s}^{*}=\left|i_{s}^{*}\right| \cos \theta_{s}^{*}, \\
i_{a s}^{*}=\left|i_{s}^{*}\right| \sin \theta_{s}^{*}, \\
i_{b s}^{*}=\left|i_{s}^{*}\right| \sin \left(\theta_{s}^{*}-\frac{2 \pi}{3}\right), \\
i_{c s}^{*}=\left|i_{s}^{*}\right| \sin \left(\theta_{s}^{*}+\frac{2 \pi}{3}\right),
\end{gathered}
$$

where

$$
\theta_{s}^{*}=\theta_{f}+\theta_{T}^{*}=\theta_{r}+\theta_{\mathrm{sl}}^{*}+\theta_{T}^{*}
$$

The implementation of IFOC on a CSI fed IM is shown in Figures 8 and 9. The torque command $i_{T}^{*}$ is generated as a function of the speed error signal generally processed through a PI controller. The flux command $i_{f}^{*}$ can be given directly or as a function of speed. The rotor position $\theta_{r}$ can be measured with an encoder and converted into necessary digital information for feedback. There has been a substantial amount of research in the development of rotor flux observers for field orientation that are compensated for variations in parameters by their feedback corrections. Digital implementation of integrators for the estimation of rotor flux of an IM from the stator voltages and stator currents poses problems associated with the offset in the sensor amplifiers.



FIGURE 8: Simplified diagram for IFOC method.



FIGURE 9: Stator current generator.

Traditional low-pass filters can replace the integrator. So, in this work, rotor flux estimated using low pass filter is described. The instantaneous flux linkage can be computed using the measured d-axis stator current using (40), which is referred to as the current model as follows:

$$
\lambda_{r}=\frac{L_{m} i_{d s}}{1+\tau_{r} s} .
$$

The theoretical concepts of IFOC method for CSI fed IM drive discussed in Sections 5.1 and 5.2 are verified through simulation using the Simulink toolbox of MATLAB. The detailed simulations results are presented in Section 7.1.

\section{DTC for CSI Fed IM Drives}

Variable speed drives are used in all industries to control precisely the speed of electric motors driving loads ranging from pumps and fans to complex drives on paper machines, rolling mill cranes, and similar drives. The most modern method for these drives is direct torque and stator flux vector control method usually called DTC. The VSI fed version has been realized in an industrial way by $A B B$, by using the theoretical background proposed by Takahashi and Ohmori [22] and Depenbrock [23]. This solution is based both on field oriented control (FOC) as well as on the direct selfcontrol theory. The idea is that motor flux and torque are used as primary control variables which is contrary to the way in which traditional AC drives control input frequency and voltage, but is in principle similar to what is done with a DC drive, where it is much more straightforward to achieve. 
Casadei et al. [24] has described that by controlling motor torque directly, DTC provides dynamic speed accuracy equivalent to closed loop AC and DC systems and torque response times that are 10 times faster. It is also claimed that the DTC does not generate noise like that produced by conventional PWM AC drives. This work describes a new modular approach to implement DTC method on a CSI fed IM drive, the simulation implementation procedure. The dynamic response of the drive is analyzed and presented.

6.1. Mathematical Modeling of DTC Control Method. The DTC method is developed from Babaei and Heydari [10]. From Krause et al. [15], in the stationary reference frame, the stator voltage and flux equation can be written as

$$
\begin{gathered}
v_{s}=R_{s} i_{s}+\frac{d \lambda_{s}}{d t}, \\
\lambda_{s}=\int\left(v_{s}-R_{s} i_{s}\right) d t=\lambda_{\alpha s}+j \lambda_{\beta s}, \\
\left|\lambda_{s}\right|=\sqrt{\lambda_{\alpha s}^{2}+\lambda_{\beta s}^{2}}, \\
\angle \varphi_{s}=\tan ^{-1}\left(\frac{\lambda_{\beta s}}{\lambda_{\alpha s}}\right),
\end{gathered}
$$

where $R_{s}$ is the stator resistance and $\lambda_{s}$ is the stator flux vector in the stationary reference frame. $\left|\lambda_{s}\right|$ and $\angle \varphi_{s}$ are the amplitude and position of stator flux vector, respectively.

In DTC of CSI fed IM, it is desirable to determine the stator current reference so that the torque and stator flux follow their reference values, Babaei and Heydari [10]. The proposed DTC system is based on the stator flux oriented (SFO) reference frame. In this rotating reference frame, it is written as

$$
\lambda_{q s}=0, \quad \lambda_{d s}=\left|\lambda_{s}\right| \angle \varphi_{s},
$$

where $d$ and $q$ are the real and imaginary axes in the SFO reference frame. Therefore, the torque equation is rewritten as

$$
T_{e}=\frac{3}{2}\left(\frac{P}{2}\right) \frac{1}{\omega_{b}}\left(\lambda_{d s} i_{q s}\right),
$$

where, $i_{q s}$ is the imaginary part of the stator current vector in the SFO reference frame. Therefore, if $\left|\lambda_{s}^{*}\right|$ and $T_{e}^{*}$ are stator flux magnitude and torque references, respectively, the imaginary part of the stator current reference vector which leads to torque and stator flux magnitude references is as follows:

$$
i_{q_{s}}^{*}=\frac{2}{3} \frac{1}{P} \frac{T_{e}^{*}}{\left|\lambda_{s}^{*}\right|} .
$$

Because of the existence of a capacitor in the control system and its corresponding losses, when (47) is used to control the torque for all rotor speeds, the control system will not be accurate enough.

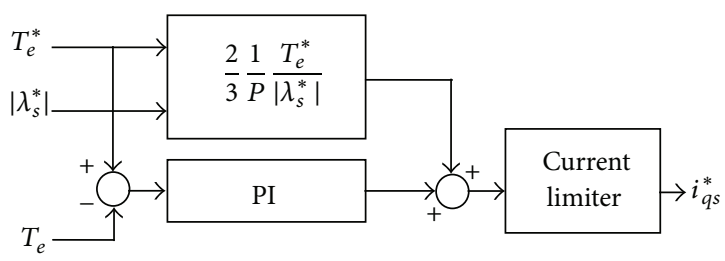

FIGURE 10: $q$-axis reference current calculator.

In order to have a more accurate torque control, the block diagram shown in Figure 10 is used to calculate $i_{q s}^{*}$. This block diagram is a combination of (47) and a simple PI controller. This controller removes the steady-state error and leads to an accurate control. The coefficients of this controller must be small enough so that it remains stable, and the ripples in $i_{q s}^{*}$ are limited, because a ripple of $i_{q s}^{*}$ results in a ripple of the generated torque. If only a PI is used, $i_{q s}^{*}$ will have a large value of ripple, and the torque response time will be very large. Therefore, in order to have a faster transient response of torque, it is necessary to use (47). In DTC method with VSI, the real part of voltage vector $\left(v_{d}\right)$ in the stator flux reference frame leads to direct control of stator flux magnitude.

Therefore, using the real part of the stator current vector in the stator flux reference frame, it is possible to control the flux magnitude indirectly. In order to obtain the real part of the stator current reference, a simple PI controller is used. The input of this PI controller is the error that resulted from the comparison between the reference stator flux magnitude and the estimated flux value. In order to control the motor current in all cases, especially in the starting mode, the output of this PI controller must be limited between proper values. The output signal of the PI controller is the real part of reference stator current $i_{d s}^{*}$.

Therefore, the stator current reference vector that leads to control the IM stator flux and torque is as follows:

$$
\begin{aligned}
& i_{s,(d q)}^{*}=i_{d s}^{*}+j i_{q s}^{*}, \\
& \left|i_{s}^{*}\right|=\sqrt{i_{d s}^{* 2}+i_{q s}^{* 2} .}
\end{aligned}
$$

The obtained reference current vector is in the stator flux reference frame. In order to generate it by SVM of the CSI, it must be transferred to the stationary reference frame. To do that, the stator flux position is used to transfer this vector from the stator flux reference frame to the stationary reference frame as follows:

$$
\begin{aligned}
i_{s,(\alpha \beta)}^{*} & =i_{\alpha s}^{*}+j i_{\beta s}^{*}=\left(i_{d s}^{*}+j i_{q s}^{*}\right) \cdot e^{j \varphi_{s}} \\
& =\left|i_{s}^{*}\right| \angle\left(\varphi_{s}+\tan ^{-1}\left(\frac{i_{q s}^{*}}{i_{d s}^{*}}\right)\right) .
\end{aligned}
$$

This reference current vector must be generated in the CSI first and then applied to the motor after removing its harmonics with filtering capacitor. This current has a nearly sinusoidal waveform that leads to a nearly sinusoidal voltage in motor terminals after feeding the motor and passing through 




FIGURE 11: Block diagram schematic of the proposed DTC.

motor impedances. The speed and stator flux control of an IM with DTC method is shown in Figure 11. Separate PI controllers are used to control the speed and flux. The input to the speed controller is the error caused by comparing the reference speed and the rotor speed. The output of this controller is the imaginary part of stator current vector $i_{q s}^{*}$, which is limited to a proper value.

\section{Results and Discussion}

7.1. Simulation Results. The simulation models of IOL, IFOC, and DTC control methods for CSI fed IM drive systems are developed and simulated using MATLAB simulation software. From the simulation results, dynamic performances of the developed drives have been individually analyzed mainly using the sensitivity tests. Here, the results of all the drives are compared with one another. The tests that are chosen for the comparison are step changes in the reference speed and torque of the motor drive.

The first test is step change in reference speed which is useful when trying to change from one speed to another. The next test is step change in reference torque that would be useful in identifying the controller with a high torque response. Change in speed reference is the first test that is done to compare the motor drives.

The results of this test can be seen in the Figures 12, 13, and 14. The speed command is varied from 0 to its rated value. The speed response of IOL drive is faster and has the settling time of 0.5 second range, while DTC and IFOC drives perform similarly but slower than IOL (settling time of less than 1 second).

The second test, as mentioned earlier, is the torque step test. The results of this test can be seen in Figures 12 to 14. The torque reference is varied from 0 to its rated value. The speed response of IFOC drive is faster and has the settling time of 0.2 seconds, while IOL and DTC drives perform similarly (settling time of less than 0.5 second).

During this test, the motor torque response of DTC drive is almost instantaneous within the 0.2 second range, while IFOC drive closely follows behind it. IOL and vector based $V / f$ have slower torque response than all other Vector Control techniques.
TABLE 1: Prototype motor parameters.

\begin{tabular}{lccc}
\hline \multicolumn{3}{c}{$1 \mathrm{Hp}, 3$ phase, star connected, 4 pole, $415 \mathrm{~V}, 1.8 \mathrm{~A}, 50 \mathrm{~Hz}$} \\
\hline Stator resistance & $0.087 \Omega$ & $\begin{array}{c}\text { Stator \& rotor } \\
\text { leakage reactance } \\
\text { Ragnetizing }\end{array}$ & $0.8 e^{-3} \mathrm{H}$ \\
Rotor resistance & $0.228 \Omega$ & $\begin{array}{c}\text { Magnce } \\
\text { reactance }\end{array}$ & $34.7 e^{-3} \mathrm{H}$ \\
\hline
\end{tabular}

7.2. Experimental Results. Brief experimental results are presented for IOL method and DTC method using TMS320F2812 DSP based hardware setup. Figure 15 shows the schematic diagram for the hardware setup of the proposed laboratory prototype CSI fed induction motor drive. The induction motor ratings are given in Table 1. The inverter consists of CM75TL-12NF. The gate driving signal is developed by using Texas instruments DSP processor TMS320F2812 DSP. The software used to develop programs for TMS320F2812 DSP is by code composer studio and Matlab/Simulink. The processor contains the program that is downloaded to the computer.

The clock speed of the DSP is $150 \mathrm{MHz}$, and it is capable of 32-bit operations. The on board available flash memory is $2.048 \mathrm{Mb}$. It was created specifically for motor control operation, and therefore Park's and Clark's transformations are conveniently built in. Another convenient feature is that it has sixteen 12-bit ADC pins that allow for a high degree of precision while taking many possible measurements.

The above experimental result of IOL method of vector control technique in Figure 16 shows the fast settling time with feed forward control compared to feedback technique. Similarly the experimental result shown in Figure 17 depicts a greater torque response within 0.2 seconds compared to other vector control techniques. With this experimental verification, it is clear that IOL is adaptive for speed response and DTC is more suitable for torque response controlled drives.

From Tables 2 and 3, it seems that the dynamic speed and torque performance of all four drives using change in speed reference. It is evident from the table that IOL drive has the best speed response, with DTC and IFOC occupying positions next to it. It is also evident that DTC drive has the best instantaneous torque response, with IFOC and IOL next to it.

\section{Conclusion}

This paper presents a new approach in mathematical modeling of a 3-phase induction motor drive. Mathematics concepts are used in developing the simulation and implementation of IOL, IFOC, and DTC methods for CSI fed IM drives, In this paper, a rotor flux based reference frame control method for PWM CSI fed IM with simplified simulation circuits has been developed in which the motor speed and torque follow the references closely in all the three vector control methods. However a CSI fed induction motor drive has some drawbacks such as slower dynamic response and bulky, overall size due to the requirement of large smoothing 


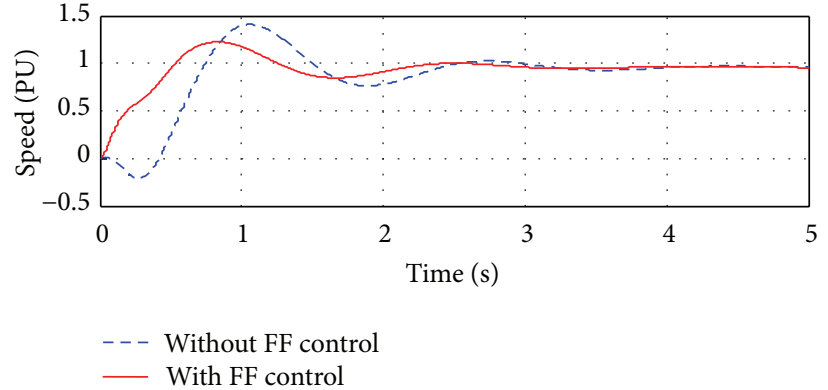

(a)

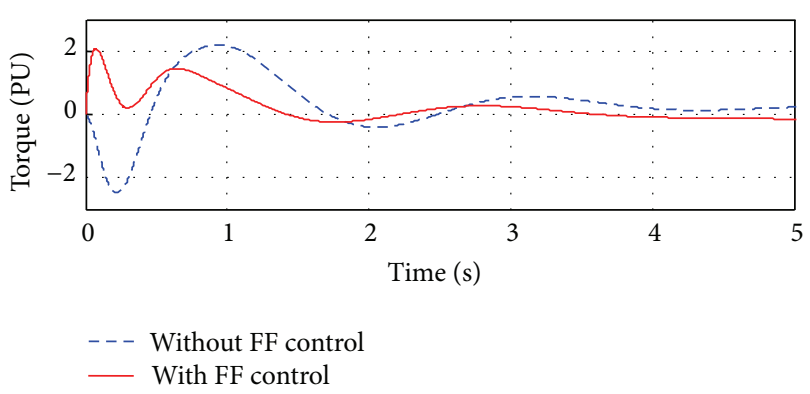

(b)

FIGURE 12: Speed, torque response of IOL control method.

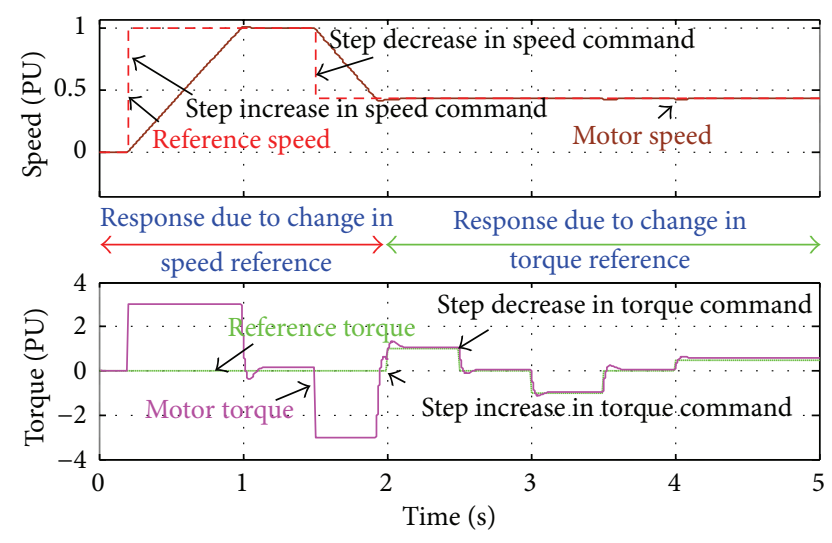

FIGURE 13: Speed, torque response of IFOC method.



FIGURE 14: Speed, torque response of DTC method.

inductor at its dc source end, and also a CSI drive system with on-line control strategy is more complex compared to a VSI drive due to the CSI gating requirements. But depending on some particular applications, its advantages can at times outweigh its disadvantages, hence rendering it as a suitable choice for certain applications. From the results, it is concluded that DTC drive is the top most performer for wide range of torque control applications (load varying

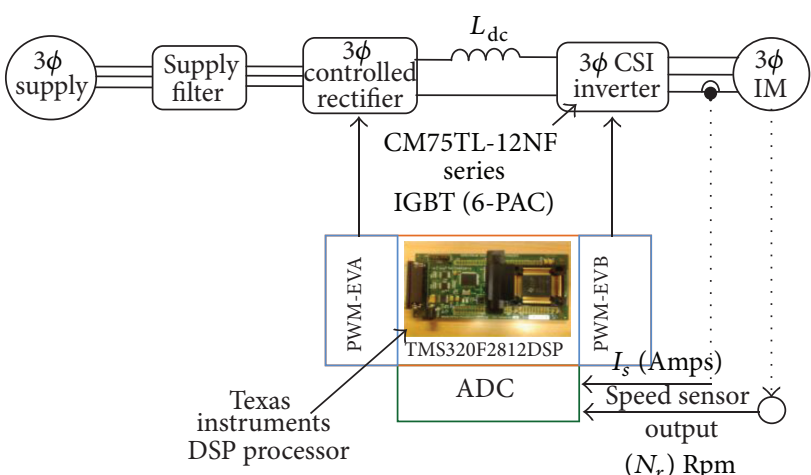

FIGURE 15: Schematic diagram of the hardware setup of CSI fed IM.

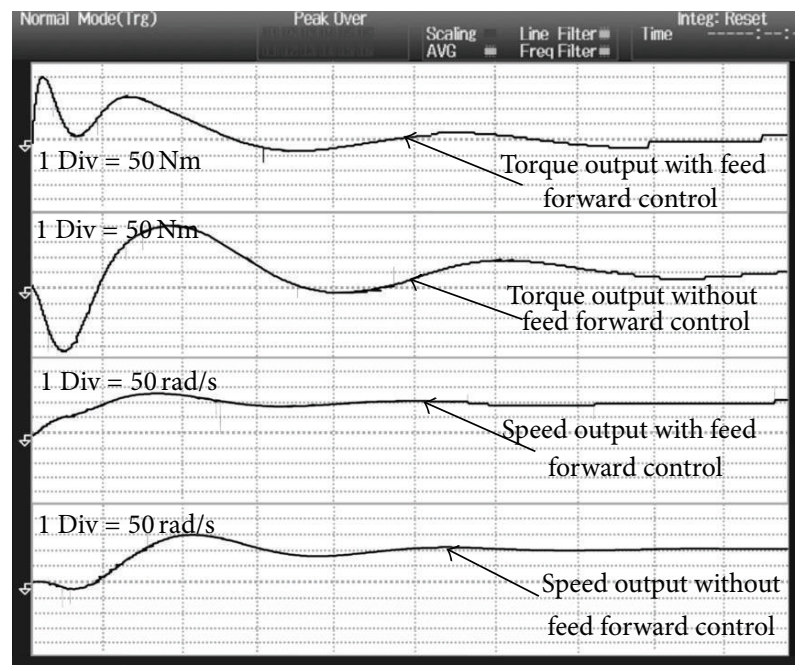

FIGURE 16: Experimental result torque-speed response of IOL control method.

applications) with respect to change in speed as well as torque references. IOL drive is the good performer for speed control applications with respect to change in speed reference, and IFOC drive is the good performer for speed control applications with respect to change in torque reference. Hence for industrial drive applications with the requirement of torque 




Figure 17: Experimental result of torque-speed response of DTC control method.

TABLE 2: Transient response results for step change in speed reference command.

\begin{tabular}{lccc}
\hline $\begin{array}{l}\text { Control } \\
\text { methods }\end{array}$ & $\begin{array}{c}\text { Settling time } \\
\left(t_{s}\right) \text { in ms }\end{array}$ & $\begin{array}{c}\text { Rising time } t_{r} \\
\text { in ms }\end{array}$ & $\begin{array}{c}\text { Maximum peak } \\
\text { overshoot }\left(M_{p} \%\right)\end{array}$ \\
\hline \multicolumn{4}{c}{ Motor speed response } \\
IOL & 1152 & 134 & 163 \\
IFOC & $\mathbf{5 6 6}$ & $\mathbf{7 9}$ & $\mathbf{2 6}$ \\
DTC & 958 & 454 & 142 \\
\hline \multicolumn{5}{r}{} & 798 & 323 & 139 \\
$V / f$ & Motor torque response \\
IOL & 1121 & 632 & 214 \\
IFOC & 954 & 82 & 194 \\
DTC & 958 & 75 & 275 \\
\hline
\end{tabular}

TABle 3: Transient Response results for Step change in Torque reference Command.

\begin{tabular}{lccc}
\hline $\begin{array}{l}\text { Control } \\
\text { methods }\end{array}$ & $\begin{array}{c}\text { Settling time } \\
\left(t_{s}\right) \text { in ms }\end{array}$ & $\begin{array}{c}\text { Rising time } t_{r} \\
\text { in ms }\end{array}$ & $\begin{array}{c}\text { Maximum peak } \\
\text { overshoot }\left(M_{p} \%\right)\end{array}$ \\
\hline \multicolumn{4}{c}{ Motor speed response } \\
V/f & 1133 & 44 & 132 \\
IOL & 421 & 4 & 5 \\
IFOC & $\mathbf{2 6 3}$ & $\mathbf{1 1 7}$ & $\mathbf{3}$ \\
DTC & 496 & 272 & 7 \\
\hline \multicolumn{5}{l}{ Motor torque response } \\
IOL & 1235 & 391 & 153 \\
IFOC & 892 & 75 & 81 \\
DTC & 215 & 54 & 151 \\
\hline
\end{tabular}

to be controlled, direct torque control method is the most efficient way to reach the desired operation of the drive to handle the load. If speed is to be controlled then IOL method is efficient with change in speed reference and IFOC method is efficient with change in torque reference.

\section{Symbols}

$\omega_{b}: \quad$ Base speed

$\dot{\lambda}_{r}^{r}$ : $\quad$ Change in rotor flux w.r.t in rotor reference frame

$\dot{\lambda}_{s}^{s}: \quad$ Change in stator flux w.r.t in stator reference frame

$K_{i}$ : Current controller gain

$\tau_{i}: \quad$ Current controller time constant

$\tau_{i f}: \quad$ Current filter time constant

$\lambda_{d r}: \quad d$-axis rotor flux

$\lambda_{d r}^{e}: \quad d$-axis rotor flux in synchronous reference frame

$\lambda_{d s}: \quad d$-axis stator flux

$i_{\mathrm{dc}}, I_{d}$ : DC link current

$L_{\mathrm{dc}}: \quad$ DC link inductance

$V_{\mathrm{dc}}: \quad$ DC link voltage

$\alpha: \quad$ Delay angle or firing angle

$\lambda_{q r}: \quad q$-axis rotor flux

$\lambda_{q r}^{e}: \quad q$-axis rotor flux in synchronous reference frame

$\lambda_{q s}: \quad q$-axis stator flux

$\lambda_{r}$ : $\quad$ Rotor flux

$L_{r}$ : Rotor inductance

$x_{r}^{\prime}: \quad$ Rotor reactance referred from stator

$R_{r}^{\prime}$ : $\quad$ Rotor resistance referred from stator

$\omega_{r}: \quad$ Rotor speed

$\theta_{\mathrm{sl}}: \quad$ Slip angle

$\omega_{\text {sll }}: \quad$ Slip speed

$\tau_{s}: \quad$ Speed controller time constant

$K_{t e}:$ Torque coefficient

$i_{\alpha s}: \quad \alpha$-axis stator current in stationary reference frame

$i_{\beta s}: \quad \beta$-axis stator current in stationary reference frame.

\section{Conflict of Interests}

The authors declare that there is no conflict of interests regarding the publication of this paper.

\section{References}

[1] K. P. Phillips, "Current-source converter for AC motor drives," IEEE Transactions on Industry Applications, vol. 8, no. 6, pp. 679-683, 1972.

[2] T. A. Lipo and E. P. Cornell, "State-variable steady-state analysis of a controlled current induction motor drive," IEEE Transactions on Industry Applications, vol. IA-11, no. 6, pp. 704-712, 1975.

[3] R. Palaniappan, J. Vithayathil, and S. K. Datta, "Principle of a dual current converter for AC motor drives," IEEE Transactions on Industry Applications, vol. IA-15, no. 4, pp. 445-452, 1979.

[4] M. Kaimoto, M. Hashi, T. Yanase, and T. Nakano, "Performance improvement of current source inverter-fed induction motor drives," IEEE Transactions on Industry Applications, vol. 18, no. 6, pp. 703-711, 1982.

[5] R. Krishnan, J. F. Lindsay, and V. R. Stefanovic, "Design of anglecontrolled current source inverter-fed induction motor drive," IEEE Transactions on Industry Applications, vol. 19, no. 3, pp. 370-378, 1983. 
[6] M. P. Kazmierkowski and H.-J. Koepcke, "A simple control system for current source inverter-fed induction motor drives," IEEE Transactions on Industry Applications, vol. IA-21, no. 4, pp. 617-623, 1985.

[7] M. Hombu, S. Ueda, and A. Ueda, "A current source GTO inverter with sinusoidal inputs and outputs," IEEE Transactions on Industry Applications, vol. 23, no. 2, pp. 247-255, 1987.

[8] M. Veerachary, "Optimal control strategy for a current source inverter fed induction motor," Computers and Electrical Engineering, vol. 28, no. 4, pp. 255-267, 2002.

[9] M. Salo and H. Tuusa, "A vector-controlled PWM currentsource-inverter-fed induction motor drive with a new stator current control method," IEEE Transactions on Industrial Electronics, vol. 52, no. 2, pp. 523-531, 2005.

[10] M. Babaei and H. Heydari, "Direct torque control of pulse width modulation current source inverter-fed induction motor by novel switching method," Electric Power Components and Systems, vol. 38, no. 5, pp. 514-532, 2010.

[11] D. G. Holmes, B. P. McGrath, and S. G. Parker, "Current regulation strategies for vector-controlled induction motor drives," IEEE Transactions on Industrial Electronics, vol. 59, no. 10, pp. 3680-3689, 2012.

[12] R. Krishnan, Electric Motor Drives Modeling, Analysis, and Control, Prentice Hall of India, 2002.

[13] P. C. Krause and C. H. Thomas, "Simulation of symmetrical induction machinery," IEEE Transaction on Power Apparatus and Systems, vol. 84, no. 11, pp. 1038-1053, 1965.

[14] B. K. Bose, Power Electronics and Motor Drives: Advances and Trends, Academic Press, 2006.

[15] P. C. Krause, O. Wasynczuk, and S. D. Sudhoff, Analysis of Electric Machines and Drive Systems, Wiley-IEEE Press, New York, NY, USA, 2002.

[16] W. H. Wonham, "On pole assignment in multi-input controllable linear systems," IEEE Transactions on Automatic Control, vol. 12, no. 6, pp. 660-665, 1967.

[17] B. Wu, G. R. Slemon, and S. B. Dewan, "Eigenvalue sensitivity analysis of GTO-CSI induction machine drives," IEEE Transactions on Industry Applications, vol. 30, no. 3, pp. 767-775, 1994.

[18] H. W. Smith and E. J. Davison, "Design of industrial regulators Integral feedback and feed forward control , PROC.IEE," Proceedings of the Institution of Electrical Engineers, vol. 119, no. 8, pp. 1210-1216, 1972.

[19] F. Blaschke, "A new method for the structural decoupling of A.C. induction machines," in Proceedings of the IFAC, pp. 1-15, Duesseldorf, Germany, October 1971.

[20] F. Blaschke, "The principle of field-orientation as applied to the transvector closed-loop control system for rotating-field machines," Siemens Revenue, vol. 34, pp. 217-220, 1972.

[21] P. Vas, Electrical Machines and Drives, Oxford University Press, London, UK, 1992.

[22] I. Takahashi and Y. Ohmori, "High-performance direct torque control of an induction motor," IEEE Transactions on Industry Applications, vol. 25, no. 2, pp. 257-264, 1989.

[23] M. Depenbrock, "Direct self-control (DSC) of inverter-fed induction machine," IEEE Transactions on Power Electronics, vol. 3, no. 4, pp. 420-429, 1988.

[24] D. Casadei, G. Serra, A. Tani, and L. Zarri, "Assessment of direct torque control for induction motor drives," Bulletin of the Polish Academy of Sciences: Technical Sciences, vol. 54, no. 3, pp. 237254, 2006. 


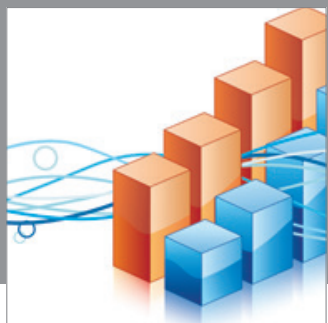

Advances in

Operations Research

mansans

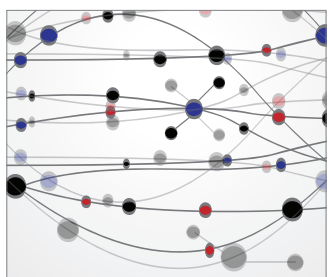

The Scientific World Journal
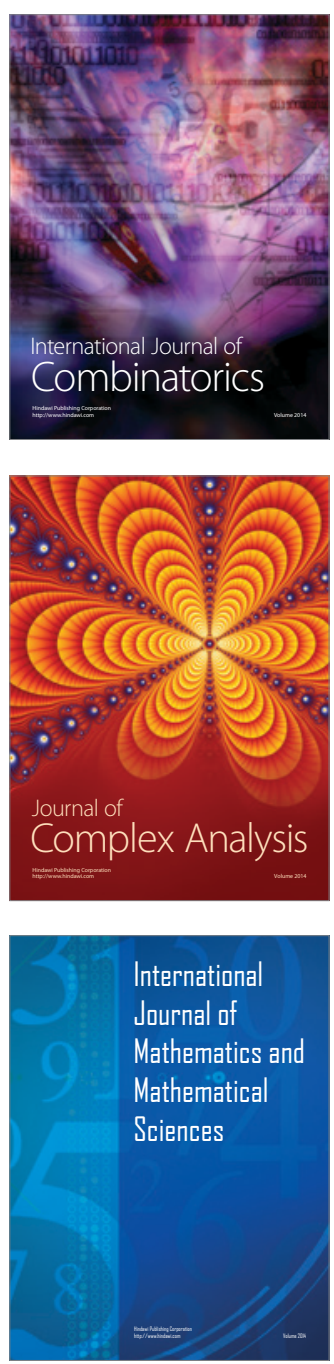
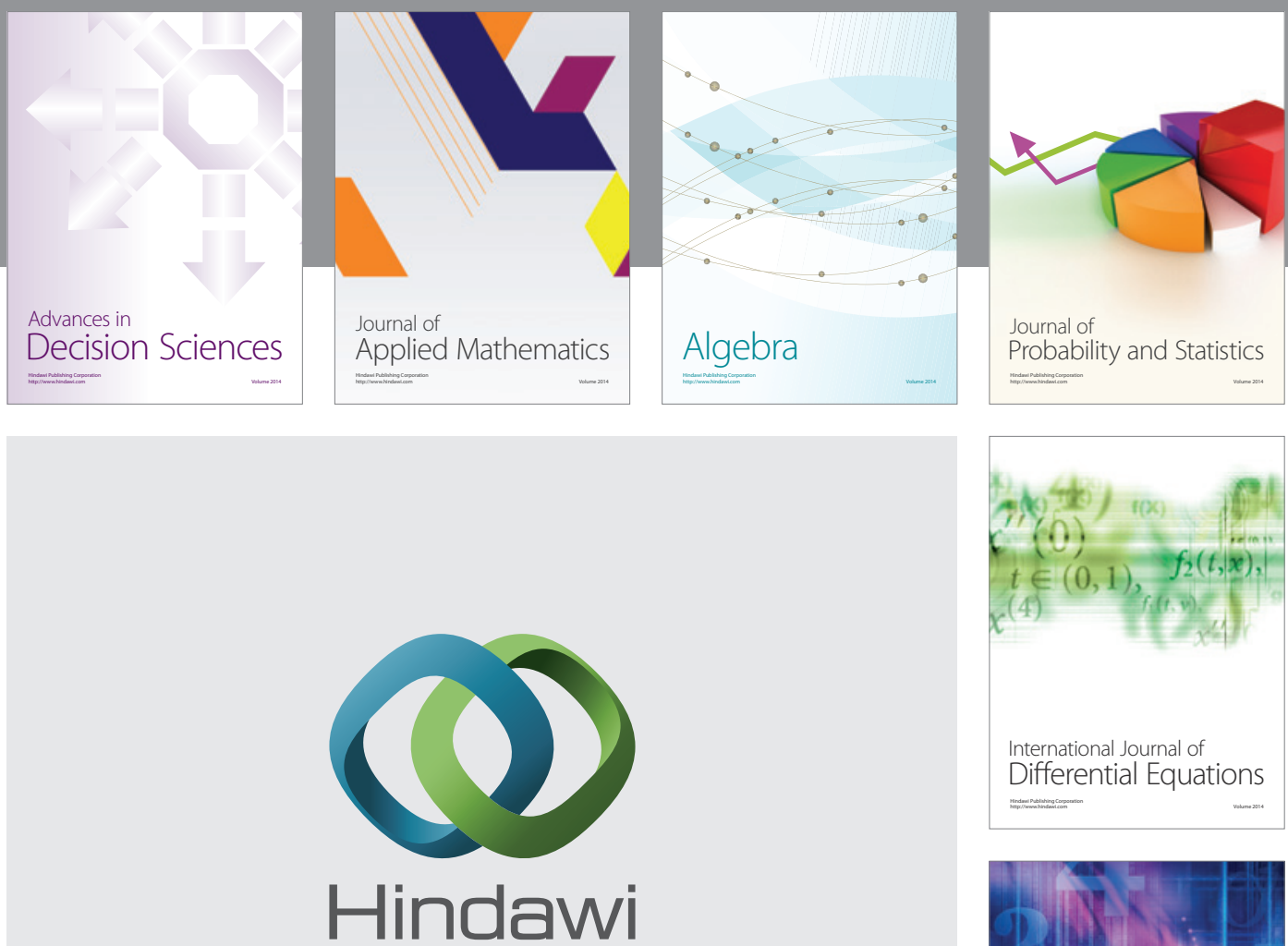

Submit your manuscripts at http://www.hindawi.com
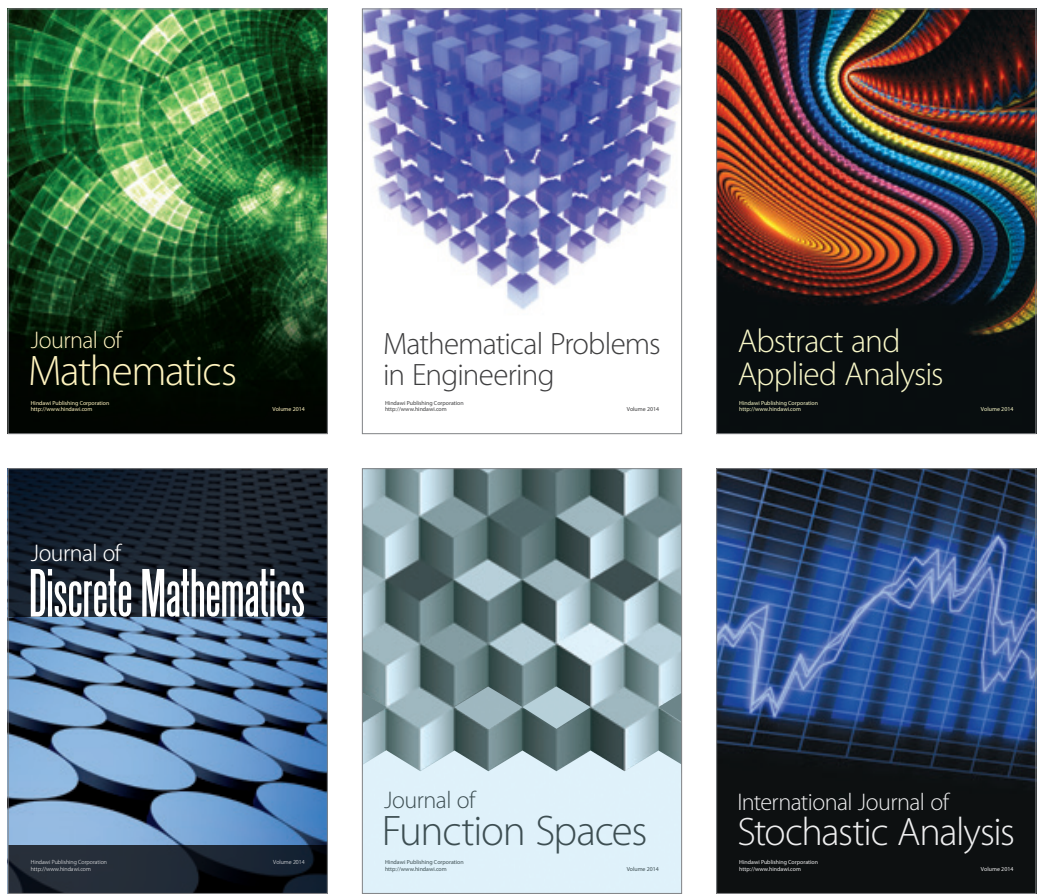

Journal of

Function Spaces



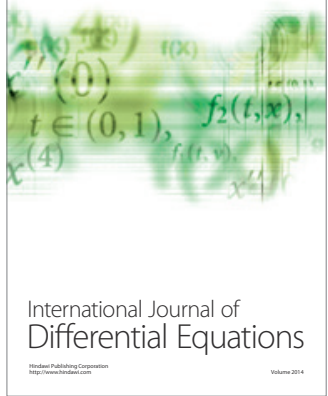
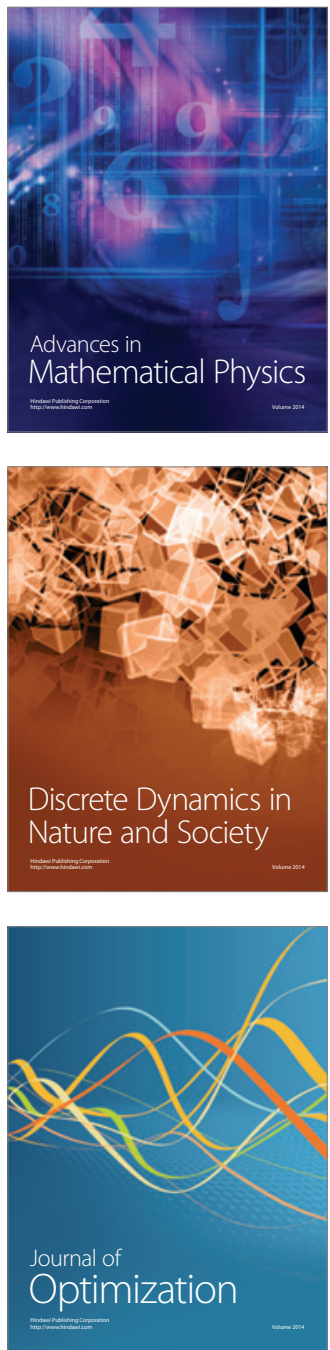